\title{
Interferência de Brachiaria plantaginea Sobre Características Agronômicas, Componentes do Rendimento e Produtividade de GRÃos do MILHO ${ }^{1}$
}

\author{
Brachiaria plantaginea Interference in the Agronomic Characteristics, Yield Components and \\ Grain Yield of Corn
}

\author{
SPADER, V. ${ }^{2}$ e VIDAL, R.A. ${ }^{3}$
}

\begin{abstract}
RESUMO - O grau de interferência causado pelas plantas daninhas na produtividade da cultura de milho pode ser variável, dependendo de qual componente é mais influenciado pela interferência e da contribuição deste componente no rendimento da cultura. Um experimento foi conduzido a campo, durante o ano agrícola 1998/99, na EEA/UFRGS, em Eldorado do Sul-RS, com o objetivo de determinar o efeito da interferência da planta daninha Brachiaria plantaginea (BRAPL) nas características agronômicas, componentes do rendimento e produtividade da cultura de milho. O milho, híbrido AG 5011, foi cultivado no sistema de semeadura direta, sucedendo a cultura de aveia-preta. A adubação do milho foi feita na linha de semeadura com $600 \mathrm{~kg} \mathrm{ha}^{-1}$ da fórmula NPK 15-20-20 e em cobertura com 100 e $150 \mathrm{~kg} \mathrm{ha}^{-1}$ de N aos 20 e 40 dias após a emergência (DAE), respectivamente. Para obter diferentes densidades de BRAPL nas 60 unidades experimentais estudadas, foram utilizados, em pré-emergência, cinco herbicidas, aplicados em diversas doses. A densidade de BRAPL variou entre 0 e 160 plantas por $\mathrm{m}^{2}$. A estatura das plantas de milho não foi afetada pela densidade de BRAPL, e o número de plantas estéreis aumentou linearmente com o incremento da infestação, enquanto o número de espigas por planta reduziu de forma linear com o aumento da densidade. O número de grãos por espiga, peso do grão e rendimento total de grãos foram reduzidos através de uma tendência sigmoidal, com o aumento da infestação. O componente do rendimento que mais contribuiu para a produtividade de grãos do milho foi o número de grãos por espiga.
\end{abstract}

Palavras-chave: planta daninha, competição, plantio direto.

\begin{abstract}
The degree of weed interference in corn yield varies, depending on which component is mostly affected by the interference, and on its contribution to corn productivity. An experiment was conducted at Eldorado do Sul-RS, Brazil, during 1998/99 growing season, to determine the effect of Brachiaria plantaginea (BRAPL) interference in the agronomic characteristics, yield components and grain yield of corn. The corn hybrid AG 5011 was planted under no-till system. The crop was fertilized at planting with $600 \mathrm{~kg} \mathrm{ha}^{-1}$ of NPK 5-20-20, and late applications with 100 and $200 \mathrm{~kg} \mathrm{ha}^{-1}$ of $\mathrm{N}$ at 20 and 40 days after crop emergence (DAE). In order to obtain variable densities of BRAPL in the treatments, plots were treated with five different herbicides applied in preemergence at various rates. BRAPL density ranged from 0 to 160 plants per $\mathrm{m}^{2}$. Corn plant height was not affected by BRAPL, whereas the number of sterile plants increased and the number of ears per plant decreased with increased weed infestation. Number of grain per ear, grain weight and grain yield decreased in a sigmoidal pattern with increased weed density. The yield component that contributed the most to corn grain yield was number of grain per ear.
\end{abstract}

Key words: weed, competition, no-till.

\footnotetext{
Recebido para publicação em 23/12/1999 e na forma revisada em 25/4/2000.

2 Eng.-Agr ${ }^{\circ}$., aluno do Curso de Mestrado no Programa de Pós-Graduação em Fitotecnia da FA/UFRGS; ${ }^{3}$ Eng.-Agr ${ }^{\circ}$., Ph.D., Professor do Departamento de Plantas de Lavoura, FA/UFRGS, Caixa Postal 776, 91501-970 Porto Alegre-RS. Pesquisador do CNPq. <vidal@if.ufrgs.br>
} 


\section{INTRODUÇÃO}

As plantas daninhas apresentam grande capacidade competitiva, porque exploram eficientemente os recursos do meio, como água, luz e nutrientes, reduzindo a sua disponibilidade para as culturas. O efeito da interferência das plantas daninhas sobre o rendimento das culturas agrícolas pode ser variável, dependendo de qual o componente do rendimento é mais influenciado pela interferência e da contribuição que este componente representa para o rendimento da cultura. A cultura do milho, embora seja considerada competitiva (Heemst, 1986), pode ser severamente afetada pela interferência de plantas daninhas, reduzindo o crescimento e a produtividade de grãos, devendo-se prevenir a interferência no período compreendido entre 15 e 45 dias após a sua emergência (Pitelli, 1985).

Os principais componentes do rendimento de grãos do milho são o número de espigas por unidade de área, o número de grãos por espiga e o peso de grãos (Mundstock, 1999). O número e o tamanho de espigas de milho normalmente são os parâmetros mais afetados pela interferência das plantas daninhas (Mundstock \& Silva, 1989). Com isso, a competição das plantas daninhas reduz o rendimento de grãos de milho (Merotto Jr. et al., 1997). Rossi et al. (1996) relatam que a interferência de plantas daninhas reduziu em $15 \%$ o tamanho de espigas de milho e em $28 \%$ o peso de grãos, resultando em $32 \%$ de perdas no rendimento de grãos. Assim, o conhecimento da capacidade e da intensidade de interferência das diferentes espécies daninhas sobre os componentes do rendimento das culturas é importante para o desenvolvimento de técnicas que promovam melhorias no manejo, visando o aumento do rendimento de grãos e a redução dos prejuízos causados pelas plantas daninhas.

Das plantas daninhas infestantes da cultura do milho, Brachiaria plantaginea (BRAPL) é a gramínea de maior ocorrência na região Sul do Brasil (Kissmann, 1991). Esta espécie é bastante competitiva, provocando prejuízos consideráveis ao rendimento e à qualidade de grãos (Kissmann, 1991; Fleck, 1996). Merotto Jr. et al. (1997) relatam que o rendimento de grãos de milho pode ser reduzido em até 90\% pela interferência de plantas de BRAPL.
Estudos relacionados à infestação desta planta daninha com os componentes de rendimento do milho são escassos na literatura. O objetivo deste estudo foi determinar o efeito da interferência de Brachiaria plantaginea nos componentes do rendimento, na produtividade de grãos e em outras características agronômicas da cultura do milho.

\section{MATERIAL E MÉTODOS}

O experimento foi conduzido durante a primavera-verão de 1998/99, na Estação Experimental Agronômica da Universidade Federal do Rio Grande do Sul, em Eldorado do Sul-RS. O solo da área experimental é classificado como Podzólico Vermelho Escuro, distrófico (Espírito Santo, 1988), com 38\% de argila, pH em água de 5,8, matéria orgânica de $2,2 \%, 8$ ppm de fósforo e $260 \mathrm{ppm}$ de potássio.

O milho, híbrido AG 5011, foi semeado no dia 8 de outubro de 1998, no sistema de semeadura direta, sucedendo a cultura de aveia preta. A adubação do milho foi feita nas linhas de semeadura com $600 \mathrm{~kg} \mathrm{ha}^{-1}$ da fórmula NPK 5-20-20. Realizou-se adubação nitrogenada de cobertura com 100 e $150 \mathrm{~kg}$ de N/ha aos 20 e 40 dias após a emergência (DAE) da cultura, quando as plantas de milho estavam nos estádios $\mathrm{V}_{4} \mathrm{e} \mathrm{V}_{8}$ (quatro e oito folhas completamente expandidas), respectivamente.

As densidades de BRAPL foram obtidas com cinco herbicidas, aplicados em duas doses, três testemunhas infestadas e duas testemunhas capinadas durante todo o ciclo do milho. Todos os tratamentos foram repetidos quatro vezes, totalizando 60 unidades experimentais. A área útil das parcelas foi de 8,0 x 1,6 m, contendo duas fileiras de milho, espaçadas de 0,80 m e com 5,6 plantas por metro, perfazendo população de 70.000 plantas de milho ha-1 após o desbaste, realizado aos 10 DAE.

Os herbicidas, com as respectivas doses ( $\left.\mathrm{kg} \mathrm{ha}^{-1}\right)$, foram: acetochlor $(2,5$ e 3,4), metolachlor $(2,4$ e 2,9$)$, isoxaflutole $(0,06$ e $0,07)$, pendimethalin $(1,25$ e 1,59$)$ e trifluralin $(1,8$ e 2,4). Esses tratamentos possibilitaram a emergência de diferentes densidades de plantas de BRAPL, as quais foram determinadas aos 50 dias após a emergência da cultura (DAE), contando-se as plantas num quadrado 
medindo 0,5 m de lado, em duas amostragens por unidade experimental.

Os herbicidas foram aplicados imediatamente após a semeadura do milho, utilizando pulverizador costal pressurizado com gás carbônico $\left(\mathrm{CO}_{2}\right)$, equipado com barra de dois metros e cinco bicos tipo leque 80.03. A pressão foi mantida constante com $150 \mathrm{kPa}$, proporcionando volume de calda equivalente a $220 \mathrm{~L} \mathrm{ha}^{-1}$. Para o controle das plantas daninhas dicotiledôneas, foi aplicado atrazine $\left(2,0 \mathrm{~kg} \mathrm{ha}^{-1}\right)$ em toda a área do experimento, em pré-emergência, utilizando um pulverizador tratorizado. A área experimental foi mantida irrigada por aspersão, distribuindo-se $20 \mathrm{~mm}$ de água em intervalos aproximados de quatro dias, até o estádio de maturação fisiológica do milho.

Avaliou-se a resposta das plantas de milho à interferência de BRAPL através da estatura de planta, da percentagem de plantas sem espiga, do número de grãos por espiga, do peso de mil grãos e do rendimento de grãos. Para determinação da estatura de planta foram avaliadas 10 plantas por parcela, medindo-se a distância entre o colo da planta e o ápice do pendão, aos 10 dias após o florescimento. A contagem do número total de plantas de milho por parcela e do número de plantas sem espiga foi feita cinco dias antes da colheita, durante a qual foram contadas as espigas de cada unidade experimental, determinando-se o número de espigas por planta. Os grãos de milho de cada parcela foram pesados e, em seguida, foi retirada uma amostra de $300 \mathrm{~g}$ para determinação da umidade, corrigindo-se o peso total de grãos de cada parcela para umidade de $13 \%$. Foram contados e pesados 500 grãos por amostra, extrapolando-se o peso para mil grãos. A relação entre peso da amostra e peso de mil grãos forneceu o número de grãos da amostra e, assim, foi possivel calcular o número de grãos por unidade experimental, o qual foi dividido pelo número de espigas, obtendo-se o número médio de grãos por espiga. A produtividade de grãos de cada parcela foi extrapolada para 1 ha.

Foram feitas regressões entre todas as variáveis estudadas e a densidade de plantas de BRAPL, com auxílio dos programas computacionais ORIGIN e SANEST, em nivel de significância de 5\% de probabilidade.

\section{RESULTADOS E DISCUSSÃO}

A estatura de planta de milho não foi influenciada pela interferência de BRAPL até o nível de infestação de 160 plantas por $\mathrm{m}^{2}$ (Figura 1a). Contudo, o número de plantas estéreis aumentou linearmente com o incremento no nível de infestação, chegando a 13\% com 160 plantas por $\mathrm{m}^{2}$ (Figura $1 \mathrm{~b}$ ), afetando o número de espigas de milho por área. Mundstock \& Silva (1989) e Merotto Jr. et al. (1997) também verificaram aumento do número de plantas estéreis de milho com níveis crescentes de infestação de plantas daninhas.

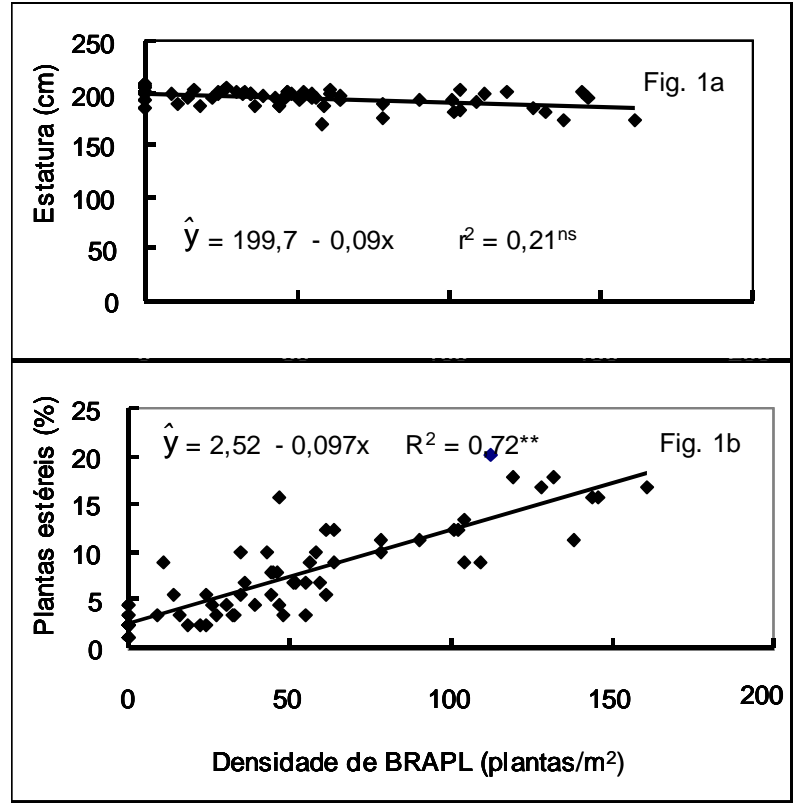

Figura 1 - Efeito de densidades de Brachiaria plantaginea (BRAPL) na estatura de planta e no percentual de plantas estéreis de milho (ns = não-significativo; ** significativo, $\mathrm{P}<0,01)$. EEA/UFRGS, Eldorado do Sul, RS, 1998/99.

A interferência da BRAPL afetou todos os componentes do rendimento do milho avaliados. O número de espigas por planta foi reduzido de forma linear com o aumento do nível de infestação (Figura 2a), enquanto o número de grãos por espiga (Figura 2b), o peso de grão (Figura 2c) e o rendimento de grãos (Figura $2 d)$ apresentaram resposta sigmoidal.

A curva de resposta sigmóide, obtida nas variáveis número de grãos por espiga, peso de grãos e rendimento de grãos, indica que, em 
densidades de até 25 plantas por $\mathrm{m}^{2}$, a interferência individual de plantas de BRAPL sobre estas variáveis é baixa, devido, provavelmente, à emergência tardia de plantas de BRAPL, uma vez que se utilizaram herbicidas residuais para obtenção das diferentes densidades das plantas daninhas.

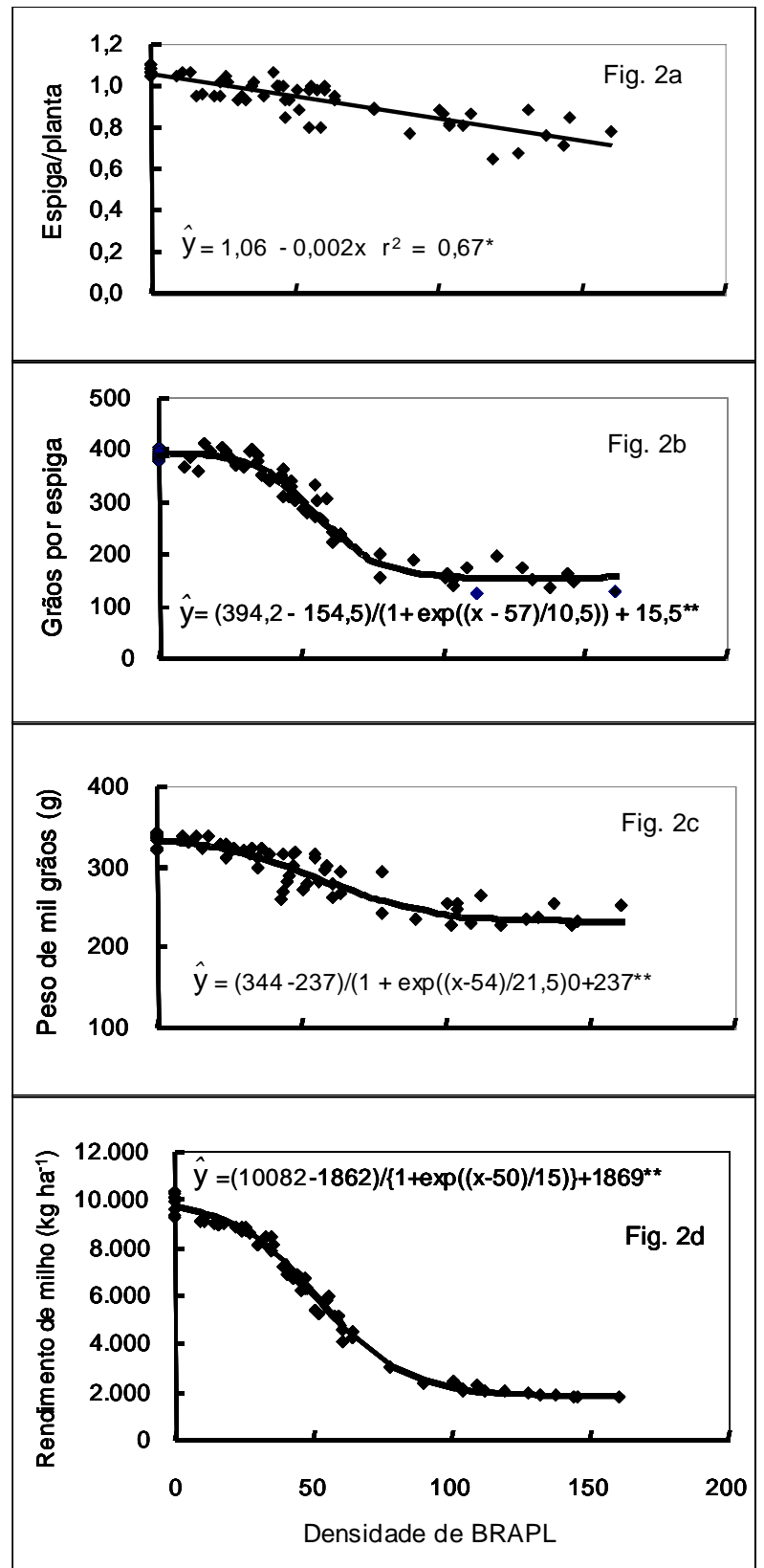

Figura 2 - Número de espigas por planta, número de grãos por espiga, peso de mil grãos e rendimento de grãos de milho, sob diferentes densidades de Brachiaria plantaginea (BRAPL), (* significativo, $\mathrm{P}<0,05$; ** significativo, $\mathrm{P}<0,01)$. EEA/UFRGS, Eldorado do Sul, RS, 1998/99.
Convém salientar que, neste experimento, os recursos do meio, como nitrogênio e água, entre outros, provavelmente não foram limitantes do desenvolvimento da cultura. Como a eficiência da planta cultivada na utilização dos recursos do meio é dependente, entre outros fatores, da época de emergência relativa às espécies daninhas, é possivel que a elevada disponibilidade de recursos possa ter favorecido a cultura na relação de competição com BRAPL. De fato, até a data da primeira adubação de cobertura a infestação era baixa, indicando que as plantas de milho tiveram rápido crescimento inicial, sombreando a área e, conseqüentemente, tendo vantagem em relação à BRAPL na competição por luz e outros recursos do meio.

Quando a densidade de BRAPL ficou compreendida entre 25 e 83 plantas por $\mathrm{m}^{2}$, verificouse que cada indivíduo teve o máximo de impacto no rendimento de grãos da cultura. Acima de 83 plantas por $\mathrm{m}^{2}$, novamente o efeito de cada planta daninha, além das já existentes, foi pouco pronunciado, sendo essa resposta atribuída à redução e à sobreposição da área de influência de cada planta daninha. A BRAPL, na densidade de 160 plantas por $\mathrm{m}^{2}$ diminuiu em 33, 56, 29 e 79\% o número de espigas por planta, o número de grãos por espiga, o peso de grãos e o rendimento de grãos de milho, respectivamente (Figura 2).

A definição do número de espigas por planta ocorre entre os estádios $\mathrm{V}_{6}$ e $\mathrm{V}_{8}$ (Hanway, 1963), coincidindo com a fase final do período crítico de prevenção da interferência de plantas daninhas na cultura do milho. O estresse provocado pela interferência da BRAPL neste período pode ter prejudicado o processo de diferenciação das gemas laterais para espigas. Além disso, a permanência da interferência após este período provavelmente afetou o desenvolvimento dessas estruturas, reduzindo o número de espigas exteriorizadas por planta e os demais componentes do rendimento, após o pendoamento.

A densidade de BRAPL não apresentou correlação com estatura de planta de milho, porém correlacionou-se positivamente com a percentagem de plantas estéreis (Tabela 1). O percentual de plantas estéreis correlacionouse negativamente com o rendimento de grãos (Tabela 1), mostrando que o nível crescente de infestação de BRAPL aumenta a quantidade 
de plantas sem espiga, reduzindo a produtividade de grãos da cultura do milho.

Entre os componentes do rendimento, o mais afetado pelo aumento da infestação foi o número de grãos por espiga, seguido pelo número de espigas por planta e pelo peso de grão (Tabela 1). A definição do número de grãos por espiga ocorre durante o período de florescimento, após a exteriorização da inflorescência masculina e dos estigmas (Hanway, 1963). O estresse decorrente da interferência de plantas daninhas pode ter prejudicado a polinização devido à defasagem no tempo entre a receptividade dos estigmas e a maturação dos grãos de pólen, reduzindo o número de óvulos fecundados, ou pode ter promovido o abortamento dos óvulos fecundados, afetando o número de grãos formados. Outros autores relatam que a semeadura de plantas de cobertura do solo em consórcio com milho, a partir de 20 dias após a emergência da cultura, reduziu o número de grãos por espiga e o peso de grãos do milho (Abdin et al., 1998). De acordo com os autores, no período de florescimento e enchimento de grãos do milho, algumas espécies de plantas de cobertura apresentavam grande desenvolvimento vegetativo, afetando as plantas de milho.

O estresse causado por falta de luz fotossinteticamente ativa durante a fase vegetativa do milho atrasou a emissão do pendão e dos estigmas, enquanto apenas a exteriorização dos estigmas foi atrasada quando a falta de luz ocorreu no período reprodutivo. Assim, o déficit luminoso prejudica a fertilização, pois dificulta o sincronismo entre a liberação do pólen e a emissão dos estigmas, reduzindo o número de grãos formados (Early et al., 1967).
Especula-se que o estresse causado pela infestação de BRAPL tenha afetado, também, a capacidade fotossintética das plantas de milho durante o período de enchimento de grãos, reduzindo a quantidade de amido armazenado nos grãos e, conseqüentemente, o peso de grão. O peso de grão do milho é definido no período entre emissão dos estigmas e maturação fisiológica pela quantidade de carboidratos acumulados no processo de fotossintese (Daynard \& Kannenberg, 1976). Aggarwal \& Sekhon (1991) verificaram correlação positiva do tempo decorrido entre o pendoamento, a emissão dos estigmas e a maturação fisiológica com os componentes do rendimento e com o rendimento de grãos da cultura.

A densidade crescente de BRAPL afetou os componentes do rendimento e a produtividade de grãos de milho. A infestação determinou 93\% da variação do número de grãos por espiga, $82 \%$ do número de espiga por planta, $80 \%$ do peso de grãos e $96 \%$ da variação do rendimento de grãos (Tabela 1). A percentagem de plantas estéreis apresentou correlação positiva com a densidade de plantas daninhas (Tabela 1), indicando que o aumento da infestação proporciona incremento do número de plantas de milho que não produzem espiga.

O número de grãos por espiga, que foi o componente do rendimento mais prejudicado pela infestação de BRAPL, também foi, individualmente, aquele que apresentou a maior correlação com o rendimento de grãos. Já o peso de grãos foi o componente menos afetado pela interferência de BRAPL e também o que apresentou a menor correlação com o rendimento de grãos (Tabela 1).

Tabela 1 - Coeficientes de correlação para densidade de Brachiaria plantaginea (BRAPL) aos 50 dias após a emergência da cultura, componentes do rendimento, rendimento de grãos e outras características agronômicas de milho. EEA/UFRGS, Eldorado do Sul-RS, 1998/99

\begin{tabular}{|l|c|c|c|c|c|c|c|}
\hline \multirow{2}{*}{ Características } & Estatura & \multicolumn{1}{|c|}{$\begin{array}{c}\text { Plantas } \\
\text { estéreis }\end{array}$} & $\begin{array}{c}\text { Grãos por } \\
\text { espiga }\end{array}$ & $\begin{array}{c}\text { Peso de mil } \\
\text { grãos }\end{array}$ & $\begin{array}{c}\text { Espigas por } \\
\text { planta }\end{array}$ & $\begin{array}{c}\text { Rendimento } \\
\text { de grãos }\end{array}$ \\
\cline { 2 - 8 } & \multicolumn{7}{|c|}{ Coeficientes de correlação (r) } \\
\hline Densidade de BRAPL & $-0,46 \mathrm{~ns}$ & $0,85^{* *}$ & $-0,93 * *$ & $-0,80 * *$ & $-0,82^{* *}$ & $-0,96^{* *}$ \\
Estatura de planta & - & $-0,34 \mathrm{~ns}$ & $0,45 \mathrm{~ns}$ & $0,37 \mathrm{~ns}$ & $0,28 \mathrm{~ns}$ & $0,45 \mathrm{~ns}$ \\
Plantas estéreis & - & - & $-0,81^{* *}$ & $-0,77 * *$ & $-0,67 * *$ & $-0,84^{* *}$ \\
Grãos por espiga & - & - & - & $0,75^{* *}$ & $0,72^{*}$ & $0,97 * *$ \\
Peso de mil grãos & - & - & - & - & $0,60 * *$ & $0,80^{* *}$ \\
Espigas por planta & - & - & - & - & - & $0,81 * *$ \\
\hline
\end{tabular}


A interferência da BRAPL nos componentes do rendimento afetou a produtividade da cultura. A análise de correlação indicou que 97\% da variação do rendimento de grãos foi determinada pelo número de grãos por espiga, enquanto 80 e $81 \%$ foram definidos pelo peso de mil grãos e pelo número de espigas por planta, respectivamente (Tabela 1). Mundstock \& Silva (1989) verificaram que o número de espigas foi o principal componente do rendimento do milho, seguido pelo número de grãos por espiga.

Vale ressaltar que, devido ao método utilizado neste trabalho - utilização de herbicidas para se obterem diferentes densidades de BRAPL - também houve mudança no período de emergência natural da espécie. As densidades obtidas não foram estáticas, do início do experimento até a colheita, mas, como nas situações reais (Radosevich et al., 1997), a população de BRAPL aumentou gradativamente à medida que cessava o efeito residual dos herbicidas utilizados. Assim, os resultados obtidos neste trabalho limitam-se a evidenciar o efeito de BRAPL nas características agronômicas da cultura do milho apenas quando medidas de controle são realizadas precocemente e ocorrer reinfestação da área com BRAPL após a emergência da cultura.

\section{LITERATURA CITADA}

ABDIN, O., BRUCE, E.C., CLOUTIER, D., FARIS, M.A., ZHOU, X.M., SMITH, D.L. Yield and yield components of corn interseeded with cover crops. Agron. J ., v.90, n.1, p.63-68, 1998.

AGGARWAL, G.C., SEKHON, N.K. Changes induced by cowpea green manure and farmyard manure in the timing of phenological events in maize (Zea mays). J . Agric. Sci., v.117, n.1, p.157163, 1991.

DAYNARD, T.B., KANNENBERG, L.W. Relationship between length of actual and effetive filling periods and the grain yield of corn. Can. J . Plant Sci., v.56, n.1, p.237-242, 1976.

EARLY, E.B., McILRATH, W.O., SEIF, R.D., HAGEMAN, R.H. Effects of shade applied at different stages of plant development on corn (Zea mays) production. Crop Sci., v.7, n.2, p.151-156, 1967.

Planta Daninha, Viçosa-MG, v.18, n.3, p.465-470, 2000
FLECK, N.G. Interferência de papuã (Brachiaria plantaginea) com soja e ganho de produtividade obtido através do seu controle. Pesq. Agropec. Gaúcha, v.2, n.1, p.63-68, 1996.

HANWAY, J.J. Growth stages of corn (Zea mays). Agron. J ., v.55, n.3, p.487-491, 1963.

HEEMST, G.H. The influence of weed competition on crop yield. Syst. Agric., v.18, n.2, p.81-83, 1986.

KISSMANN, K. G. Plantas infestantes e nocivas. São Paulo: BASF, 1991. p.67-94.

MEROTTO Jr., A., GUIDOLIN, A.F., ALMEIDA, M.L., HAVERROTH, H.S. Aumento da população de plantas e uso de herbicidas no controle de plantas daninhas em milho. Planta Daninha, v.15, n.2, p.141-151, 1997.

MUNDSTOCK, C.M. Bases fisiológicas para aumentar o rendimento do milho no Sul do Brasil. Lages: 1999. In: REUNIÃO TÉCNICA CATARINENSE DE MILHO E FEIJÃO, 2, 1999, Lages. Resumos... Lages: UDESC/EPAGRI, 1999. v.1. p.31-38.

MUNDSTOCK, C.M., SILVA, P.R.F. Manejo da cultura do milho. Porto Alegre: Universidade do Rio Grande do Sul, 1989. 76p.

PITELLI, R.A. Interferência de plantas daninhas em culturas agrícolas. Inf. Agropec., v.11, n.129, p.16-27, 1985.

RADOSEVICH, S.R., HOLT, J.S., GHERSA, C. Weed ecology: implications for vegetation management. 2.ed. New York: Wiley \& Sons, 1997. 588p.

RETTA, A., VANDERLIP, R.L., HIGGINS, R.A., MOSHIER, L.J., FEYERHERM, A.M. Suitability of corn models for incorporation of weed and insect stresses. Agron. J ., Madison, v.83, p.757765, 1991.

ROSSI, I.H., OSUNA, J.A., ALVES, P.L.C.A., BEZUTTE, A.J. Interferência das plantas daninhas sobre algumas características agronômicas e a produtividade de sete cultivares de milho. Planta Daninha, v. 14, n.2, p.134-148, 1996. 